\title{
Approaches to Quantifying the Electronic and Steric Properties of Metallodithiolates as Ligands in Coordination Chemistry
}

\author{
Jason A. Denny and Marcetta Y. Darensbourg*
}

Department of Chemistry, Texas A\&M University, College Station, Texas 77843, United States

*Corresponding Author: marcetta@chem.tamu.edu

\begin{abstract}
The well-known steric and electronic factors developed for phosphines by Tolman have influenced the design of organometallic complexes for catalytic processes for nearly a half century. Metallodithiolates as in square planar $\mathrm{MN}_{2} \mathrm{~S}_{2}, \mathrm{MP}_{2} \mathrm{~S}_{2}$, and $\mathrm{MS}_{2} \mathrm{~S}_{2}$ complexes utilize cisdithiolates as mono- or bidentate donors to exogeneous metals, such as low valent metal carbonyls and nitrosyls wherein their established donor abilities are similar to phosphines. The highly asymmetric heterobimetallic complexes have folded "butterfly" structures deriving from their hinged $\mathrm{M}(\mu-\mathrm{SR})_{2} \mathrm{M}^{\prime}$ cores. Analysis of the electronic factors of representatives from a broad series of $\mathrm{MN}_{2} \mathrm{~S}_{2}$ complexes is referenced to electrochemical redox events as well as the vibrational spectroscopy of diatomic ligand reporters. Steric properties are assessed from XRD studies that yield common metric parameters such as bite angle; they define as well the hinge angle of the bridging thiolate, and the wedge that encompasses the largely planar ligands in bidentate bonding. Adaptation of various approaches to defining ligand steric factors such as the solid angle and percent-buried-volume permits comparison with ligands such as phosphines or simple imines. According to the percent buried volume, spacial requirements of $\mathrm{MN}_{2} \mathrm{~S}_{2}$ ligands
\end{abstract}


are within a range of 33-36\% and in-between the 1,2-bis-diphenylphosphinomethane, dppm, (38\%) and bipyridine (30\%). The asymmetry and tunability of such $\mathrm{MN}_{2} \mathrm{~S}_{2}$ metalloligands for both electronic and steric control are prospects for applications in catalytic processes.

Keywords: Steric factor, buried volume, metalloligands, thiolate, heterobimetallic

\section{Outline}

1. Introduction

2. Electron Donor Ability

3. Steric Effects: Cones, Wedges, and Percent Buried Volume

3.1. Cone Angles (for Monodentate $\mathrm{MN}_{2} \mathrm{~S}_{2}$ Ligands) and Wedge Angles (for Bidentate $\mathrm{MN}_{2} \mathrm{~S}_{2}$ Ligands)

\subsection{Percent Buried Volume Calculations}

4. Conclusion

\section{Introduction}

There are a large number of coordination complexes featuring first row transition metals in contiguous, tetradentate ${ }^{-} \mathrm{S}-\mathrm{N}-\mathrm{N}-\mathrm{S}^{-}$or $\left[\mathrm{N}_{2} \mathrm{~S}_{2}\right]^{2-}$ ligation. With appropriate $\mathrm{N}$ to $\mathrm{S}$ and $\mathrm{N}$ to $\mathrm{N}$ hydrocarbon linkers the wrap around the metal yields a cis orientation of the terminal thiolate that may serve as aggregation sites for additional, exogeneous metals. Thus, the $\mathrm{MN}_{2} \mathrm{~S}_{2}$ complexes themselves, Figure $1 \mathrm{~A}$ ), represent a unique class of metalloligands in that the lone pairs of the sulfurs in such cisdithiolates are ideally oriented to act as bidentate ligands to a single, Figure $1 \mathrm{C}$ ), or multiple exogenous metals [1]. When available receivers are limited, 
monodentate coordination is also possible, Figure 1B), highlighting the possibility of hemilability. In comparison to anionic thiolates without such coordinate covalent bonds, these S-donors are "tamed" by the transition metal, with donor abilities lying between those of $\mathrm{RS}^{-}$ and RSR' [2]. In fact, studies of a series of $(\mathrm{HL}) \mathrm{W}(\mathrm{CO}){ }_{4}$ complexes that report the effect of ligand on CO stretching frequencies, similarly to the Tolman electronic parameter approach [3], established that the thiolate sulfurs in $\mathrm{NiN}_{2} \mathrm{~S}_{2}$ metalloligands are better donors than conventional bidentate ligands such as 1,2- bis(diphenylphosphino)methane, dppm, or bipyridine, Table 1 [4]. The metallodithiolate ligands differ drastically from the latter in that the two lone pairs on each sulfur donor site lead to geometrically ordered aggregates in various topological forms, Figure 1 [1]. Importantly, the more or less regular square planar binding conformation of the $\mathrm{N}_{2} \mathrm{~S}_{2}$ donor set can accommodate a range of metals and ion fragments such as the other group VIII divalent metal ions, $\mathrm{Pd}^{2+}$ and $\mathrm{Pt}^{2+}$, as well as cations such as $[\mathrm{V} \equiv \mathrm{O}]^{2+},[\mathrm{Zn}(\mathrm{Cl})]^{+},[\mathrm{Fe}(\mathrm{NO})]^{2+}$, and $[\mathrm{Co}(\mathrm{NO})]^{2+}$ in which the additional oxo, $\mathrm{Cl}^{-}$or NO ligand renders the metal pentacoordinate in the $\mathrm{N}_{2} \mathrm{~S}_{2}$ environment. The versatility of the $\mathrm{N}_{2} \mathrm{~S}_{2}$ donor set permits such metals to sit above the $\mathrm{N}_{2} \mathrm{~S}_{2}$ plane and achieve optimal orbital overlap in largely square pyramidal geometry. Thus, the indirect interactions of steric and electronic effects of what we will define as the endo metal (M, that within the $\mathrm{N}_{2} \mathrm{~S}_{2}$ site) on the residual S-donor ability to the exo metal (M', that attached to one or both of the cis-dithiolates) is of significance, and questions related to this coordination environment are the object of this report. 

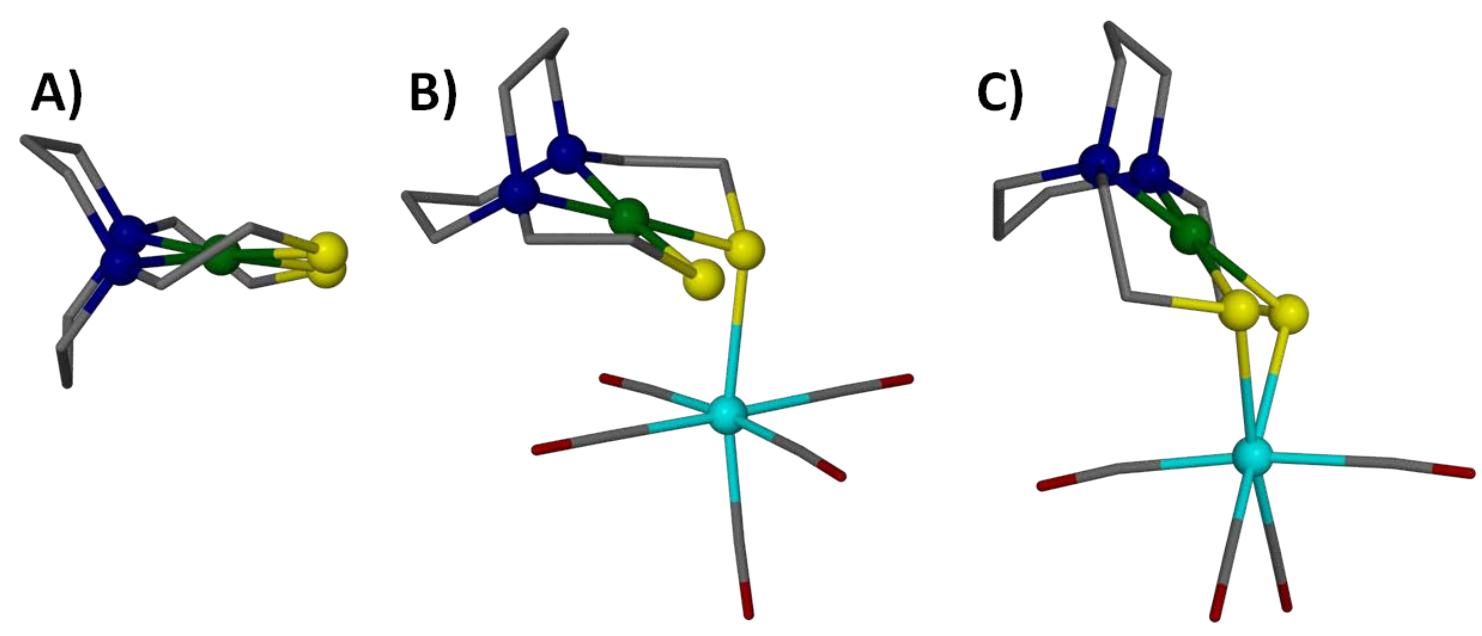

Figure 1. Structural representations of A) a free $\mathrm{MN}_{2} \mathrm{~S}_{2}$ metalloligand; B) monodentate binding of a $\mathrm{MN}_{2} \mathrm{~S}_{2}$ metalloligand, $\mathrm{M}=\mathrm{d}^{8}$ metal ion, to a secondary metal center ( $\left.\mathrm{M}^{\prime}\right)$, in this case $\mathrm{W}(\mathrm{CO})_{5}$; and $\mathrm{C}$ ) bidentate binding to $\mathrm{W}(\mathrm{CO})_{4}$. Color code: Sulfur (yellow), nitrogen (blue), carbon (gray), oxygen (red), nickel (green), and tungsten (cyan).

Table 1 contains a selection of such metallodithiolates as bidentate donors to $\mathrm{W}(\mathrm{CO})_{4}$ [48], and as monodentate ligands to $\mathrm{W}(\mathrm{CO})_{5}$ [9], $\mathrm{Fe}(\mathrm{CO})_{4}$ [10], and $\mathrm{Ni}(\mathrm{CO})_{3}$ acceptors [11], wherever valid comparisons may be found. Values derived from three methods of quantifying steric bulk are listed in Table 1: a) the "solid angle” [12]; b) our modification of Tolman’s ligand cone angle; and c) Nolan’s percent buried volume $\left(\% \mathrm{~V}_{\text {bur }}\right)[13]$. The application of each of these approaches for the sterically irregular metallodithiolate ligands will be described below, following a discussion of electron donating ability. The conclusion section further describes the scope of these metalloligands as governed by their electronic and steric properties.

\section{Electron Donor Ability}


The electronic parameter originally established by Tolman for phosphine ligands of (L) $\mathrm{Ni}^{0}(\mathrm{CO})_{3}$, assumed that the donor ability of $\mathrm{L}$ was revealed through the effect of $\mathrm{Ni}-\mathrm{CO} \pi$ back-bonding on the $v(\mathrm{CO}) \mathrm{A}_{1}$ vibrational mode; specifically, the lower the $v(\mathrm{CO})$ value, the better the donor [3]. Table 1 contains solution data (with the exception of Entry 3) in the $v(\mathrm{CO})$ region of the infrared spectrum with assignments for several metallodithiolate derivatives as compared to more common ligands. Wherever possible we give data for series of complexes in the same solvent. Entries 11-22 are all in dimethylformamide, DMF. We recognize that such comparisons are not exact and the general trend only is to be viewed with certainty. We have not listed force constants, however a more detailed analysis is given in Ref. 1. By this measure, using the $\mathrm{Ni}(\mathrm{CO})_{3}$ acceptor standard, the N-heterocyclic carbene, NHC ligand, IMes, is a better donor by ca. $20 \mathrm{~cm}^{-1}$ over that of the $\mathrm{PPh}_{3}$ ligand, entries 2 and 1 , Table 1 . Currently, the only known $\mathrm{MN}_{2} \mathrm{~S}_{2}$ metalloligand bound to a $\mathrm{Ni}(\mathrm{CO})_{3}$ fragment is that of a dimeric $\left[\mathrm{FeN}_{2} \mathrm{~S}_{2}\right]_{2}$ complex, whose structure leaves one thiolate sulfur in a terminal position that is capable of binding as a monodentate ligand to another metal. As indicated in entries 1 - 3 of Table 1, the $v(\mathrm{CO}) \mathrm{A}_{1}$ value is similar to that of the NHC ligand, and possibly a bit lower $[3,11,14]$. While the difference in media may render this comparison insignificant, the $\mathrm{NiN}_{2} \mathrm{~S}_{2}$ analogue with greater $\mathrm{Ni}_{\mathrm{d} \pi}-\mathrm{S}_{\mathrm{p}}$ antibonding, electron rich character would be expected to be much lower.

Using the $\mathrm{Fe}^{0}(\mathrm{CO})_{4}$ fragment as acceptor, entries 4 - 9 of Table 1, the data again indicate the NHC ligand, IMes, is a better donor than $\mathrm{PPh}_{3}$; the $v(\mathrm{CO})$ values for the $\mathrm{NiN}_{2} \mathrm{~S}_{2}$ as monodentate S-donor are even lower, entry 9, Table 1 [10, 15-19]. Another comparison of a $\mathrm{NiN}_{2} \mathrm{~S}_{2}$ metalloligand as monodentate ligand to the acceptor and reporter $\mathrm{W}(\mathrm{CO})_{5}$ unit, with the analogous $\mathrm{W}(\mathrm{CO})_{5} \mathrm{PPh}_{3}$ complex, again shows the former S-donor to lower the $v(\mathrm{CO})$ values by ca. $10-20 \mathrm{~cm}^{-1}$ as compared to $\mathrm{PPh}_{3}$, entries 10 and $11[9,20]$. 
In bidentate coordination the stable and well-characterized $\mathrm{MN}_{2} \mathrm{~S}_{2} \bullet \mathrm{W}(\mathrm{CO})_{4}$ series of compounds has been useful to assess the donor strength of the $\mathrm{MN}_{2} \mathrm{~S}_{2}$ metalloligand as well as for codifying steric parameters. To the list of $v(\mathrm{CO})$ IR values of several $\mathrm{NiN}_{2} \mathrm{~S}_{2}$ derivatives reported earlier and repeated here $[4,8]$, we have added some pentacoordinate complexes, entries 15, 16, 20, and 21 [5-7]. The $v(\mathrm{CO})$ IR values for the neutral $\mathrm{M}(\mathrm{NO})($ bme-dach) $(\mathrm{M}=\mathrm{Fe}$ and Co) derivatives of $\mathrm{W}(\mathrm{CO})_{4}$ are slightly higher than those of the analogous $\mathrm{Ni}^{2+}$ complexes 17 19 which are roughly equivalent. Placing the dicationic $[\mathrm{V} \equiv \mathrm{O}]^{2+}$ into the tetraanionic $\mathrm{N}, \mathrm{N}$ 'ethylene-bis(2-mercaptoacetamide), ema ${ }^{4-}$, results in a dianionic $\mathrm{W}(\mathrm{CO})_{4}$ derivative with lower $v(\mathrm{CO})$ IR values, entry 20, while the anionic $\mathrm{ZnCl}\left(\right.$ bme-dach) ${ }^{-}$and the dianionic $\mathrm{Ni}(\mathrm{ema})^{2-}$ metalloligands, entries 21 and 22, respectively, have the lowest $v(\mathrm{CO})$ IR values of all. Again, even the neutral metallodithiolate ligands rank higher in donor abilities than do the classical diphosphine (dppm) and bipyridine ligands, entries 12 - 14 [21-23]. While the donor ability of ligands does not necessarily correspond to binding ability (or metal ligand distances), the donor ability has been effective to gage the ligand's ability to stabilize higher oxidation states as might be expected for intermediates in catalytic processes involving oxidative addition reactions.

The extent to which the $\mathrm{MN}_{2} \mathrm{~S}_{2}$ ligand is a donor to an exogeneous metal, $\mathrm{M}^{\prime}$, Figure 2, may also be analyzed by electrochemistry. Using the $\mathrm{W}(\mathrm{CO})_{4}$ unit as an acceptor, the reversible one-electron reduction potentials of $\mathrm{M}\left(\right.$ bme-dach), $\mathrm{M}=\mathrm{Ni}^{2+}, \mathrm{Co}(\mathrm{NO})^{2+}$, and $\mathrm{Fe}(\mathrm{NO})^{2+}$, are observed to shift, on binding, from their free $\mathrm{MN}_{2} \mathrm{~S}_{2}$ ligand values by $+0.47 \mathrm{~V}$ ( $\mathrm{E}^{\circ}$ (referenced to $\left.\mathrm{Fc} / \mathrm{Fc}^{+}=0.0\right)-2.11$ shifts to $\left.-1.64 \mathrm{~V}\right) ;+0.49(-1.08$ to $-0.59 \mathrm{~V})$; and, $+0.61(-1.08$ to $-0.47 \mathrm{~V})$, respectively. The positive shifts on binding to the $\mathrm{W}(\mathrm{CO})_{4}$ unit are a result of electron density drained from the dithiolates by the soft Lewis acid acceptor. The differences in $\mathrm{E}^{\circ}$ values of free $\mathrm{MN}_{2} \mathrm{~S}_{2}$ for $\mathrm{M}=\mathrm{Ni}^{\mathrm{I} / \mathrm{I}}$ vs. the $\mathrm{M}=[\mathrm{M}(\mathrm{NO})]^{2+/ 1+}$ derivatives are ascribed to the delocalization 
possible in the nitrosyl derivatives. The similarity in the positive shifts of the three $\mathrm{MN}_{2} \mathrm{~S}_{2}$ metalloligands is largely consistent with the $v(\mathrm{CO})$ IR data. It should be noted that such simple interpretations of metallothiolates as ligands may be questioned in thiolate-bridged complexes where the two transition metals are of equal thiophilicity. That is, the assignment of X (the M-SR covalent bond that represents $\mathrm{X}$ as a 1-electron donor in the neutral approach to electron counting) and L (the M-SR coordinate covalent bond in which the $\mathrm{S}$ is a 2-electron donor deriving from a neutral ligand) character to the thiolate bridge in a particular $\mathrm{M}-(\mu-\mathrm{SR})-\mathrm{M}$ ' arrangement will not always be straightforward, Figure 2, and in fact may switch depending on the oxidation states of $M$ and $M^{\prime}$ [24].
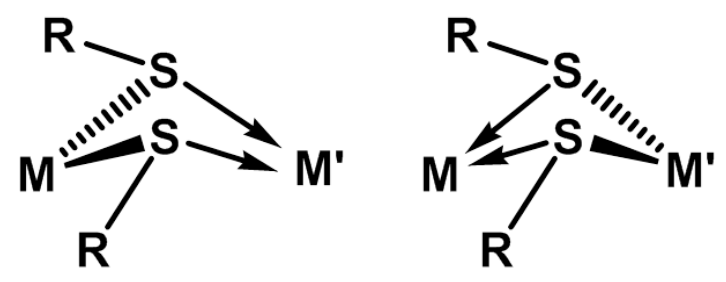

\section{$\mathbf{X} / \mathbf{L}$ bonding $\quad$ L/X bonding}

Figure 2. Representations of bridging thiolates and their respective donor types. In the first example the thiolate is an $\mathrm{X}$-donor to $\mathrm{M}$ and an $\mathrm{L}$-donor to $\mathrm{M}^{\prime}$; the second example shows a reversal of donor type and the system is now $\mathrm{L}$ and $\mathrm{X}$ to $\mathrm{M}$ and $\mathrm{M}$ ', respectively.

\section{Steric Effects: Cones, Wedges, and Percent Buried Volume}

Tolman's steric parameter, the angle of the cone that emanates from the metal and encompasses the bulk of ligands, the cone angle or LCA, was originally applied to symmetric, monodentate phosphines anchored on a pyramidal $\mathrm{Ni}(\mathrm{CO})_{3}$ unit. Tolman's LCA has remained as 
a standard comparison of ligand steric properties since it was first published in 1970 [3]. Other approaches have been developed for less symmetric and two dimensional ligands, such as $\mathrm{N}$-heterocyclic carbenes (NHCs) or pyridines and derivatives. However none have had the impact or versatility as Tolman's LCA, and in fact results are generally related back to the LCA.

Nolan et al. and Gusev have used calculated bond dissociation energies of CO ligands in (L)Ni(CO) $)_{3}$ complexes as a measure of different steric requirements of NHCs and even found extremely bulky NHCs to make the coordinatively unsaturated (L)Ni(CO) $)_{2}$ the preferred complex [14, 25]. Similarly, with PCP pincer-type ligands bound to iridium (III) small changes in steric congestion at flanking (trans) phosphines will determine penta- or hexa-coordination, thus illustrating how steric bulk can facilitate and stabilize sterically congested “open” sites [26].

Similar to Tolman's LCA a ligand's angular encumbrance expressed as a "solid cone angle", $\Omega$, was defined by Immirzi and Musco. An advantage of this approach, which is based on X-ray structural data and space-filling models, is in the accommodation of multiple conformers and compressibility of asymmetric phosphine ligands [12]. It can also reveal differences (albeit small) in the steric features of the ligand under consideration resulting from additional coordination units on the metal acceptor. Regardless, there is a general correlation with the simpler Tolman LCA.

An analysis of an extensive list of bidentate phosphine ligands by Weigand, et al., correlated the bite angle of such ligands with Immirzi's solid angle concept (the "shadow" of the as projected on the outer sphere of the complex) [27]. As expected, larger bite angles correlate with larger solid angles. These authors concluded that a generalized "equivalent cone angle" of bidentate ligands can be based on the solid angle. 

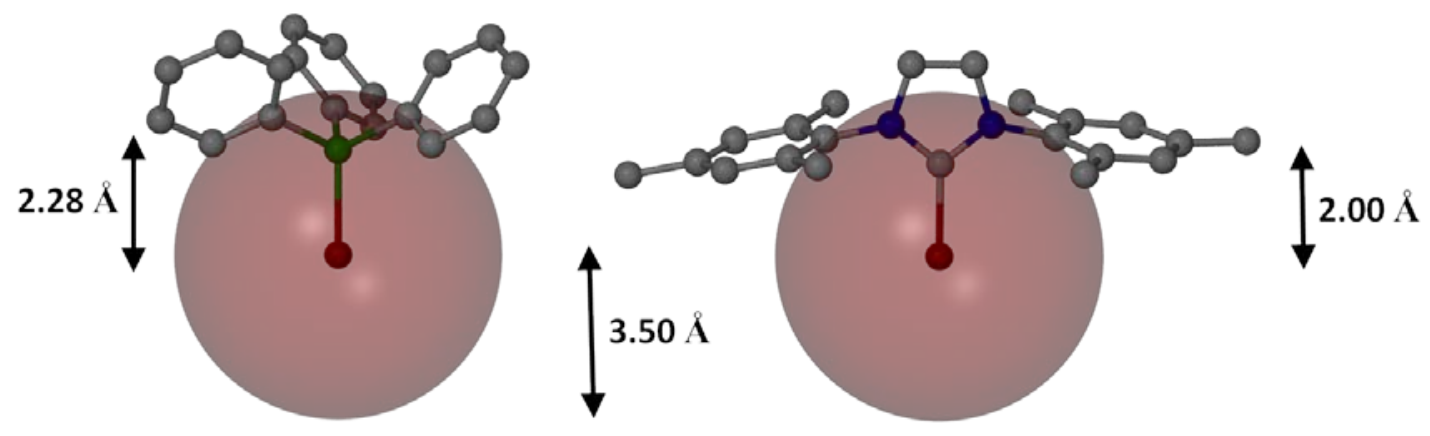

Figure 3. Models of percent buried volume, $\% \mathrm{~V}_{\text {bur, }}$ approach to $\mathrm{PPh}_{3}$ and the IMes Nheterocyclic carbene ligands referenced to a P-M bond length of $2.28 \AA$ and a C-M bond length of $2.00 \AA$. Based on spheres of radius $3.5 \AA$, the vector linking $\mathrm{M}$ and $\mathrm{P}$ or $\mathrm{M}$ and $\mathrm{C}$ is defined by the centroid of the $3 \mathrm{C}$-atoms in $\mathrm{PR}_{3}$ and the $2 \mathrm{~N}$-atoms of the $\mathrm{NHC}$, respectively.

Clavier and Nolan explored the concept of percent buried volume, $\% \mathrm{~V}_{\text {bur }}$, as might be appropriate for phosphines and the highly asymmetric and widely used N-heterocyclic carbenes, NHCs, Figure 3 [13]. This approach imbeds the ligand within a sphere of set radius from the metal center and, from the van der Waals radius of each atom within the sphere, the percent volume occupied by the ligand is calculated making use of the free online software, SambVca [28]. Once again, for phosphines, a linear correlation with Tolman LCA's was observed, $\left(\mathrm{R}^{2}=\right.$ 0.96), at M-donor atom distances of 2.00 and $2.28 \AA$ [13]. The extension of this approach with $\mathrm{Au}^{+}$as a reference metal of low coordination number for NHC's, obviated steric encumbrance from other ligands. From values determined in this way, the coauthors assessed the effect of spectator ligands on the $\% \mathrm{~V}_{\text {bur }}$ of the $\mathrm{NHC}$, finding variability in the orientation of the $\mathrm{N}$ substituents of the NHC, with concomitant differences in the $\% \mathrm{~V}_{\text {bur }}$. Ligands that have multiple conformers such as phosphines or NHC's and flexibility in their steric requirements are 
portrayed by Clavier and Nolan as having potential for enhancing catalysis by transition state stabilization [13].

Such approaches as described above have not been applied to the more complex, highly asymmetrical metalloligands such as the $\mathrm{MN}_{2} \mathrm{~S}_{2}$ complex ligands. As noted in Figure 1, the orientation of the lone pairs on the sulfur donor of $\mathrm{MN}_{2} \mathrm{~S}_{2}$ ligands renders a highly angular hinge at the $\mathrm{M}(\mu-\mathrm{SR})_{1,2} \mathrm{M}_{\mathrm{x}}$, bridge. This hinge angle is defined as the $\mathrm{M}(\mu-\mathrm{SR}) \mathrm{M}^{\prime}$ angle in Figure 1B) or the dihedral angle between the $\mathrm{MS}_{2}$ and $\mathrm{S}_{2} \mathrm{M}^{\prime}$ planes in Figure 1C). It leads to a serious bifurcation of steric hindrance at the $\mathrm{M}$ ' site and provides a challenge for establishing steric hierarchy. However, the numerous solid state structures offer a rich milieu for analysis. Herein we describe the use of X-ray crystallographic data in pursuing a Tolman LCA for monodentate binding of a $\mathrm{MN}_{2} \mathrm{~S}_{2}$ ligand, a wedge angle (taken from a side view of the $\mathrm{MN}_{2} \mathrm{~S}_{2}$ ) for bidentate binding, as well as the $\% \mathrm{~V}_{\text {bur }}$.

\subsection{Cone Angles (for Monodentate $\mathrm{MN}_{2} \mathrm{~S}_{2}$ ) and Wedge Angles (for Bidentate $\mathrm{MN}_{2} \mathrm{~S}_{2}$ )}

It appeared to us that it would be legitimate and useful to establish a ligand cone angle for the $\mathrm{MN}_{2} \mathrm{~S}_{2}$ metalloligands in monodentate complexes. Hence molecular structures from XRD were examined for the atom(s) that exhibit steric encumbrance and/or pressure on the reporter units $\mathrm{Ni}(\mathrm{CO})_{3}, \mathrm{~W}(\mathrm{CO})_{5}$, and $\mathrm{Fe}(\mathrm{CO})_{4}$. Thus each cone angle is not necessarily the largest imaginable for the $\mathrm{MN}_{2} \mathrm{~S}_{2}$ metalloligand but rather the effective cone angle for the specific system as established in the solid state structures. The cone angles for the $\mathrm{MN}_{2} \mathrm{~S}_{2}$ ligands are measured using the van der Waals radius of the sulfur and/or hydrogen that mandate the limiting surface restriction, Figure S1. By this approach the maximum, half-ligand cone angle found for the particular $\mathrm{NiN}_{2} \mathrm{~S}_{2}$ metalloligand mono-dentate bound to $\mathrm{W}(\mathrm{CO})_{5}$ in complex $\mathbf{1 1}$ is roughly 
$70^{\circ}$ which would span a full cone angle of $140^{\circ}$, should there be free rotation about the WS bond. For comparison, the LCA of $\mathrm{PPh}_{3}$ as in $\left(\mathrm{Ph}_{3} \mathrm{P}\right) \mathrm{W}(\mathrm{CO})_{5}$, is $\sim 146^{\circ}$. From $\mathrm{X}$-ray crystallography, the structures of complexes 10 and $\mathbf{1 1}$ are overlaid in Figure 4; the coincidence of a single hydrogen from each complex above the carbonyl ligands highlights the similar steric requirements of the $\mathrm{NiN}_{2} \mathrm{~S}_{2}$ and $\mathrm{PPh}_{3}$ ligands.

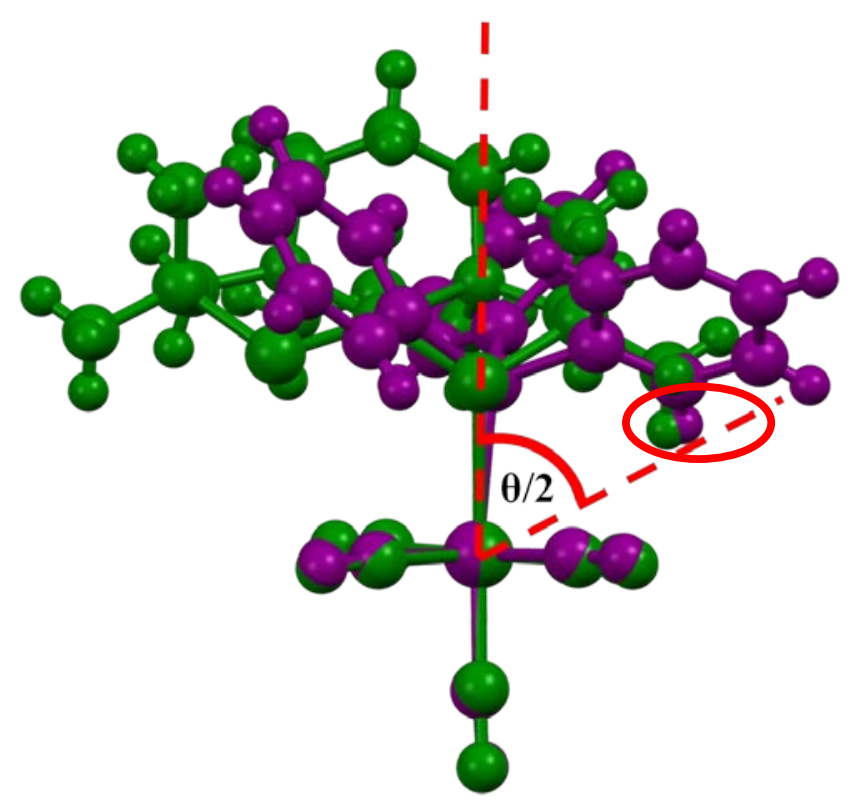

Figure 4. X-ray structure overlays of complexes 10 , $\left(\mathrm{Ph}_{3} \mathrm{P}\right) \mathrm{W}(\mathrm{CO})_{5}$, (purple) and 11, Ni(bme*daco)W(CO)5, (green) showing the similar steric requirements of the $\mathrm{NiN}_{2} \mathrm{~S}_{2}$ ligand and the $\mathrm{PPh}_{3}$ ligands. The circled $\mathrm{H}$ atoms are from the gem-dimethyl group of $\mathrm{Ni(bme*-daco)} \mathrm{(green)} \mathrm{and} \mathrm{a}$ phenyl group of $\mathrm{PPh}_{3}$, the latter describing the typical ca. $145^{\circ} \mathrm{LCA}$ of $\mathrm{Ph}_{3} \mathrm{P}$ in $\left(\mathrm{Ph}_{3} \mathrm{P}\right) \mathrm{Ni}(\mathrm{CO})_{3}$. 
A)

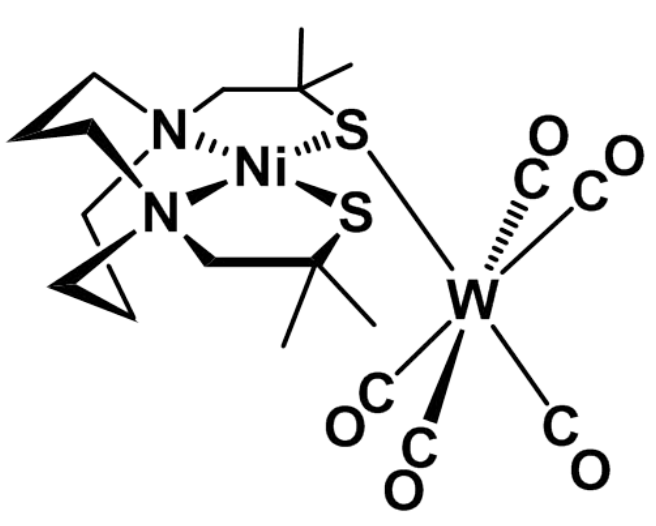

B)

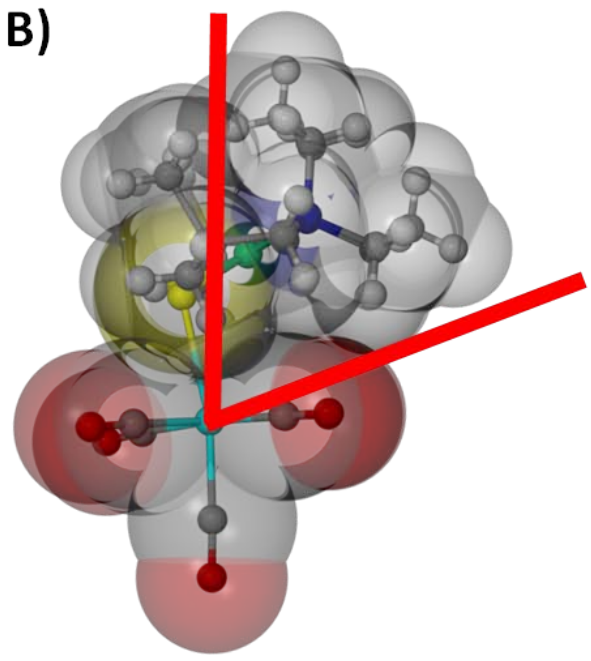

D)

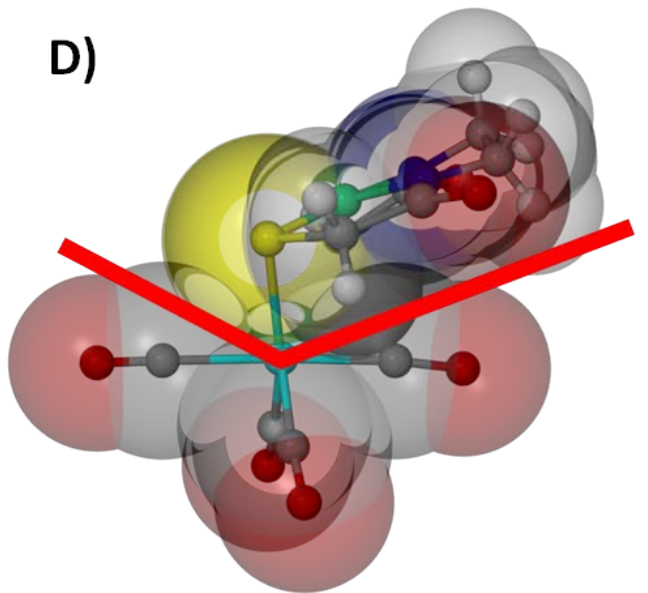

C)

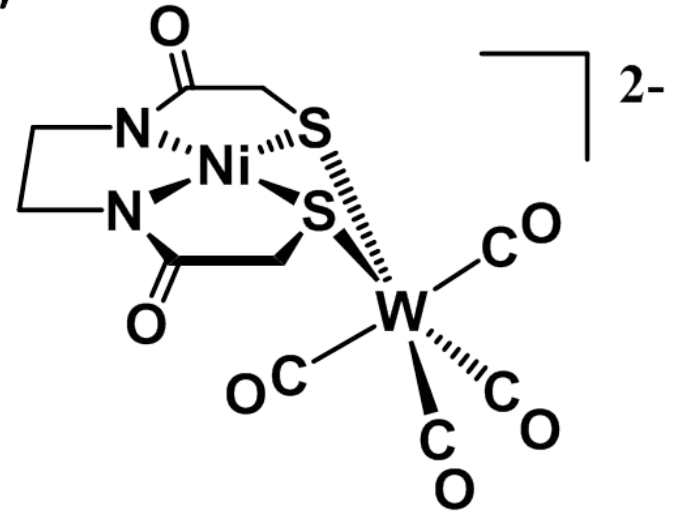

Figure 5. ChemDraw structures A) and C) and solid state structures shown in ball and stick representations with transparent space-filling models B) and D) of complexes 11 and 22, respectively. Structures A) and B) are of complex 11 in which $\mathrm{Ni}($ bme*-daco) binds monodentate to $\mathrm{W}(\mathrm{CO})_{5}$. Structures $\mathrm{C}$ ) and $\mathrm{D}$ ) show complex 22 with $\mathrm{Ni}(\mathrm{ema})^{2-}$ as a bidentate $\mathrm{MN}_{2} \mathrm{~S}_{2}$ ligand to $\mathrm{W}(\mathrm{CO})_{4}$. Note the sulfurs (yellow) and nitrogens (blue) are eclipsed.

The Ni(bme-daco) binds as a monodentate metalloligand to $\mathrm{Fe}(\mathrm{CO})_{4}$, complex 9, in an axial position of the trigonal bipyramid, as does $\mathrm{PPh}_{3}$. In this case, the ligand cone angle swept 
out by a freely rotating $\mathrm{NiN}_{2} \mathrm{~S}_{2}$ about the S-M' bond is $150^{\circ}$, which is slightly smaller than $\mathrm{PPh}_{3}$ in complex 5, $\mathrm{Fe}(\mathrm{CO})_{4} \mathrm{PPh}_{3}$, of LCA of $160^{\circ}$. Complexes 4, $\mathrm{Fe}(\mathrm{CO})_{4}\left(\eta_{1}\right.$-dppe), and 6, $\mathrm{Fe}(\mathrm{CO})_{4} \mathrm{P}^{\mathrm{t}} \mathrm{Bu}_{3}$, exhibit more steric bulk and encumbrance on the $\mathrm{Fe}(\mathrm{CO})_{4}$ unit with cone angles of $166^{\circ}$ and $172^{\circ}$, respectively. Other asymmetric ligands such as pyridine and N-heterocyclic carbenes may be described by the cone they might sweep should there be free rotation about the M-donor atom bond [29-31]. Accordingly, the small pyridine ligand in complex 7, $\mathrm{Fe}(\mathrm{CO})_{4} \mathrm{Py}$, has a cone angle of $130^{\circ}$, while the NHC derivative, $8, \mathrm{Fe}(\mathrm{CO})_{4} \mathrm{IMes}$, has the largest, $172^{\circ}$, equal to $\mathrm{P}^{\mathrm{t}} \mathrm{Bu}_{3}$ in complex 6. The only available example of a $\mathrm{MN}_{2} \mathrm{~S}_{2} \cdot \mathrm{Ni}(\mathrm{CO})_{3}$ compound is complex 3 which has the $\mathrm{FeN}_{2} \mathrm{~S}_{2}$ binding to a $\mathrm{Ni}(\mathrm{CO})_{3}$ unit with a Tolman LCA of $188^{\circ}$; for comparison that of $\mathrm{P}\left(\mathrm{C}_{6} \mathrm{~F}_{5}\right)_{3}$ measured in $\left(\mathrm{C}_{6} \mathrm{~F}_{5}\right)_{3} \mathrm{PNi}(\mathrm{CO})_{3}$ is $184^{\circ}$ [3].

Bidentate ligands such as we are considering have two prominent steric features. We define a "hinge" angle (extended from the monodentate version) as that of the intersection of the plane of the ligand which contains two donor atoms and a real or imaginary point with the plane made by the metal and the two donor atoms, Figure 5C. A second steric definition is the "wedge" angle needed to encompass the entire ligand as taken from a perspective with the donor atoms eclipsed; the center of the wedge emanates from M'. In the cases of the well-known bipyridine, 13, and dppm, 12, ligands, the hinge angle is $180^{\circ}\left( \pm 5^{\circ}\right)$ for each as expected since the donor sites have a single electron pair; however, the wedge angles are $102^{\circ}$ and $202^{\circ}$, respectively as measured in $\mathrm{M}(\mathrm{CO})_{4}$ complexes. In contrast, the steric effect of bidentate $\mathrm{MN}_{2} \mathrm{~S}_{2}$ ligands is very asymmetric due to the residual lone pairs on the two sulfurs. For example $[\mathrm{Ni}(\mathrm{ema})]^{2-}$ is a "planar" metalloligand (similar to bipy) with minimal steric requirements derived from the $\mathrm{NiN}_{2} \mathrm{~S}_{2}$ ligand itself; however, the orientation of the S-lone pairs results in a hinged bridge. For example, in complex 22 the intersection of the $\mathrm{NiS}_{2}$ and $\mathrm{WS}_{2}$ planes produce a hinge angle of 
$\sim 110^{\circ}$. As seen in complex 18 the intersection of the $\mathrm{NiS}_{2}$ and $\mathrm{WS}_{2}$ is at an angle of $\sim 130^{\circ}$ in the more highly sterically encumbered $\mathrm{Ni}\left(\mathrm{bme} \mathrm{*}^{*}\right.$-daco), i.e., the hinge angle is only $20^{\circ}$ degrees larger than that of complex 22. In terms of the extended steric component, comparisons of the wedge angles, the bulkier complex 18 is $135^{\circ}$ while the smaller $\mathrm{MN}_{2} \mathrm{~S}_{2}$ ligand in 22 yields a wedge angle of $128^{\circ}$. Due to an energy barrier of $>15 \mathrm{kcal} / \mathrm{mol}$, we have not considered a flipping process or sulfur inversion [4]. This steric pressure from the metalloligand can be seen in the deviation of linearity between the two CO ligands cis to the metalloligand (trans to each other); $\mathrm{C}-\mathrm{W}-\mathrm{C} 168^{\circ}$ and $177^{\circ}$, respectively. While the hinge angle reveals the asymmetry of the $\mathrm{MN}_{2} \mathrm{~S}_{2}$ ligand and how one side of the metal complex might be blocked, there is no discernible trend in the series of metalloligands. Therefore we have pursued the percent-buried volume approach as a possible alternative method for relating steric properties of these $\mathrm{MN}_{2} \mathrm{~S}_{2}$ ligands.

\subsection{Percent Buried Volume Calculations}

By using the online SambVca software [28], the $\% \mathrm{~V}_{\text {bur }}$ for the $\mathrm{MN}_{2} \mathrm{~S}_{2}$ complexes were measured and listed in Table 1 with visualizations shown in Figures 6-7 and S2-S4. Tables S1 and S2 list the dependence of $\% \mathrm{~V}_{\text {bur }}$ on sphere size and inclusion or exclusion of hydrogen atoms. Figure 6 shows three different views of complex 17 as metalloligand in stick, stick with transparent van der Waals'-, and space filling forms imbedded in spheres of radii 3.5, 4.0, and $4.5 \AA$, with the $\mathrm{W}$ of the $\mathrm{W}(\mathrm{CO})_{4}$ acceptor at the center of the sphere. Alternative views of complex 17 from Figure 6 are shown from the top and bottom perspective in Figure S2. A graphical display of calculated $\% \mathrm{~V}_{\text {bur }}$ using the three different sphere radii sizes shows the trend in steric bulk for the ligands is maintained, regardless of the selected sphere size, Figure S3. Thus, the calculations reported are based on a sphere of radius $3.5 \AA$ as in Nolan's recent studies 
[13]. Note from Table S1 the trend is also not affected by the inclusion of hydrogen atoms; numbers reported are thus based on calculations that exclude hydrogen atoms. 
Table 1. Lists of complexes with monodentate and bidentate ligands with v(CO) IR values reflecting electron donating properties. Steric bulk is measured using ligand cone or wedge angles, solid angles, and percent buried volume calculations all based on using solid state structures, as described in the text.

\begin{tabular}{|c|c|c|c|c|c|c|c|c|}
\hline No & Ligand (L or LL) & Complex & IR: $v(C O) \mathrm{cm}^{-1}$ & Media & $\begin{array}{l}\text { Ligand Cone or } \\
\text { Wedge Angle }\end{array}$ & Solid Angle $\boldsymbol{\Omega}^{\mathrm{n}}$ & $\begin{array}{c}\text { Percent Buried } \\
\text { Volume }^{\circ}\end{array}$ & Ref. \\
\hline 1 & $\mathrm{PPh}_{3}$ & $\mathrm{Ni}(\mathrm{CO})_{3} \mathrm{~L}$ & 2069, 1990 & $\mathrm{CH}_{2} \mathrm{Cl}_{2}$ & $145^{\mathrm{k}}$ & 4.39 & 28.7 & 3 \\
\hline 2 & IMes $^{\mathrm{a}}$ & $\mathrm{Ni}(\mathrm{CO})_{3} \mathrm{~L}$ & 2051, 1970 & $\mathrm{CH}_{2} \mathrm{Cl}_{2}$ & 168 & 5.63 & 34.0 & 14 \\
\hline 3 & $\mathrm{Fe}(\mathrm{dsdm})^{\mathrm{b}}$ & $\mathrm{Ni}(\mathrm{CO})_{3} \mathrm{~L}$ & $2048,1968,1949^{i}$ & $\mathrm{KBr}$ & 188 & 6.72 & 26.3 & 11 \\
\hline 4 & $d p p e^{c}$ & $\mathrm{Fe}(\mathrm{CO})_{4} \mathrm{~L}$ & $2052,1980,1947,1939^{i}$ & hexanes & 166 & 5.52 & 29.4 & 16 \\
\hline 5 & $\mathrm{PPh}_{3}$ & $\mathrm{Fe}(\mathrm{CO})_{4} \mathrm{~L}$ & $2050,1977,1945$ & hexanes & 160 & 5.19 & 28.7 & 18 \\
\hline 6 & $P^{t} \mathrm{Bu}_{3}$ & $\mathrm{Fe}(\mathrm{CO})_{4} \mathrm{~L}$ & $2040,1960,1920$ & $\mathrm{CH}_{2} \mathrm{Cl}_{2}$ & 172 & 5.84 & 35.1 & 17 \\
\hline 7 & pyridine & $\mathrm{Fe}(\mathrm{CO})_{4} \mathrm{~L}$ & $2042,1970,1943$ & hexanes & 130 & 3.63 & 20.6 & 15 \\
\hline 8 & IMes $^{\mathrm{a}}$ & $\mathrm{Fe}(\mathrm{CO})_{4} \mathrm{~L}$ & $2041,1960,1935,1921^{i}$ & hexanes & 172 & 5.84 & 34.0 & 19 \\
\hline 9 & $\mathrm{Ni}(\text { bme-daco })^{\mathrm{d}}$ & $\mathrm{Fe}(\mathrm{CO})_{4} \mathrm{~L}$ & $2030,1945,1926,1907^{i}$ & THF & 150 & 4.66 & 24.2 & 10 \\
\hline 10 & $\mathrm{PPh}_{3}$ & $\mathrm{~W}(\mathrm{CO})_{5} \mathrm{~L}$ & 2074, 1981, 1943 & $\mathrm{CHCl}_{3}$ & 146 & 4.44 & 23.5 & 20 \\
\hline 11 & $\mathrm{Ni}\left(\mathrm{bme}^{*}-\mathrm{daco}\right)^{\mathrm{e}}$ & $\mathrm{W}(\mathrm{CO})_{5} \mathrm{~L}$ & $2061,1971,1920,1874^{i}$ & DMF & 140 & 4.13 & 22.3 & 9 \\
\hline 12 & $d p p m^{f}$ & $\mathrm{~W}(\mathrm{CO})_{4}(\mathrm{LL})$ & 2016, 1906, 1906, 1870 & DMF & $150 / 190 / 202 / 230^{\prime}$ & $4.66 / 6.83 / 7.48 / 8.94^{\prime}$ & 37.9 & 4,22 \\
\hline 13 & bipyridine & $\mathrm{W}(\mathrm{CO})_{4}(\mathrm{LL})$ & $2006,1886,1870,1830$ & DMF & $102 / 191^{m}$ & $2.33 / 6.89^{\mathrm{m}}$ & 30.0 & 4,23 \\
\hline 14 & piperidine & $\mathrm{W}(\mathrm{CO})_{4} \mathrm{~L}_{2}$ & 2000, 1863, 1852, 1809 & DMF & 148 & 4.55 & -------------- & 4,21 \\
\hline 15 & $\mathrm{Co}(\mathrm{NO})(\mathrm{bme}-\mathrm{dach})^{\mathrm{g}}$ & $\mathrm{W}(\mathrm{CO})_{4}(\mathrm{LL})$ & $1998,1880,1854,1827$ & DMF & 131 & 3.68 & 33.0 & 6 \\
\hline 16 & $\mathrm{Fe}(\mathrm{NO})(\mathrm{bme}-\mathrm{dach})^{\mathrm{g}}$ & $\mathrm{W}(\mathrm{CO})_{4}(\mathrm{LL})$ & $1997,1878,1851,1824$ & DMF & 136 & 3.93 & 33.8 & 6 \\
\hline 17 & $\mathrm{Ni}(\text { bme-dach })^{\mathrm{g}}$ & $\mathrm{W}(\mathrm{CO})_{4}(\mathrm{LL})$ & 1996, 1873, 1852, 1817 & DMF & 138 & 4.03 & 32.5 & 4 \\
\hline 18 & $\mathrm{Ni}\left(\mathrm{bme}^{*} \text {-daco }\right)^{\mathrm{e}}$ & $\mathrm{W}(\mathrm{CO})_{4}(\mathrm{LL})$ & 1996, 1871, 1857, 1816 & DMF & 136 & 3.93 & 35.6 & 4 \\
\hline 19 & $\mathrm{Ni}(\text { bme-daco })^{\mathrm{d}}$ & $\mathrm{W}(\mathrm{CO})_{4}(\mathrm{LL})$ & $1995,1871,1853,1819$ & DMF & 128 & 3.53 & 31.6 & 4 \\
\hline 20 & $\mathrm{VO}(\mathrm{ema})^{\mathrm{h}}$ & $\mathrm{W}(\mathrm{CO})_{4}(\mathrm{LL})$ & 1996, 1872, 1848, 1802 & DMF & 137 & 3.98 & 36.1 & 7 \\
\hline 21 & $\mathrm{ZnCl}\left(\right.$ bme-dach) ${ }^{\mathrm{g}}$ & $\mathrm{W}(\mathrm{CO})_{4}(\mathrm{LL})$ & 1988, 1861, 1836, 1801 & DMF & 143 & 4.29 & 33.8 & 5 \\
\hline 22 & $\mathrm{Ni}(\mathrm{ema})^{\mathrm{h}}$ & $\mathrm{W}(\mathrm{CO})_{4}(\mathrm{LL})$ & 1986, 1853, 1837, 1791 & DMF & 128 & 3.53 & 33.1 & 4 \\
\hline
\end{tabular}


Table 1. Continued.

${ }^{a} 1$, bis(2,4,6-trimethylphenyl)-imidazolium

${ }^{\mathrm{b}} \mathrm{N}, \mathrm{N}$ '-dimethyl-N,N'-bis(2-sulfanyl-ethyl)ethylenediamine)

'1,2-bis(diphenylphosphino)ethane

${ }^{\mathrm{d}} \mathrm{N}, \mathrm{N}$ '-bis-mercaptoethylene-1,5-diazacyclooctane

${ }^{\mathrm{e}} \mathrm{N}, \mathrm{N}$--bis(2-mercapto-2-methylpropylene-1,5-diazacyclooctane

f1,1-bis(diphenylphosphino)methane

${ }^{\mathrm{g}} \mathrm{N}, \mathrm{N}$ '-bis-mercaptoethylene-1,4-diazacycloheptane

${ }^{\mathrm{h}} \mathrm{N}, \mathrm{N}$ '-ethylene-bis(2-mercaptoacetamide)

'E band of the $v(C O)$ IR spectrum is observed as two separate peaks

'Ligand cone angles all measured in this work using hydrogen atoms that present the greatest steric encumbrance in the solid state structures

keported from Tolman Chem. Rev. 1977.[3]

'Different cone angles based on which proton is selected

${ }^{\mathrm{m}}$ Two cone angles reflect the two-dimensions of the bipyridine ligand

"Solid Angle, $\Omega$, calculated using ligand cone angle, $\theta$, derived herein; $\Omega=2 \pi(1-\cos (\theta / 2))$

Measured using the online SambVca software, see text 
$3.5 \AA$
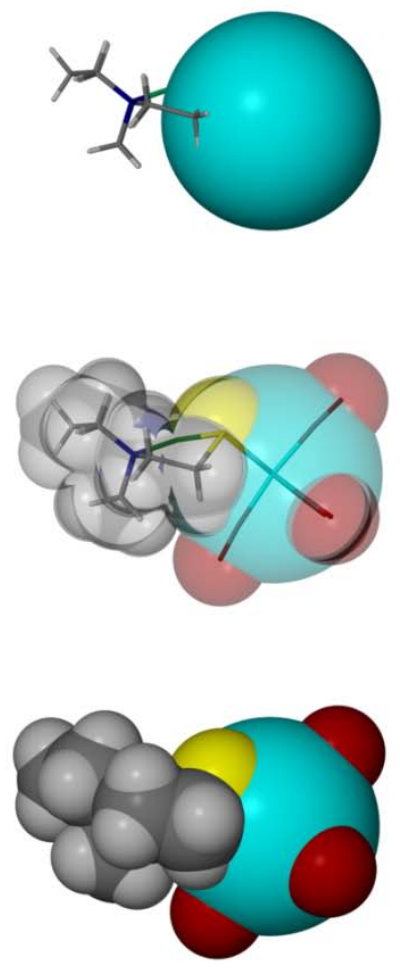

$4.0 \AA$
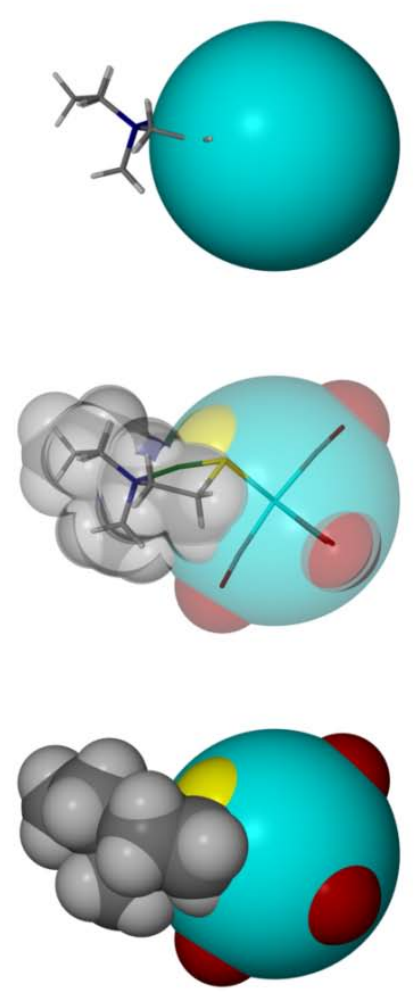

$4.5 \AA$
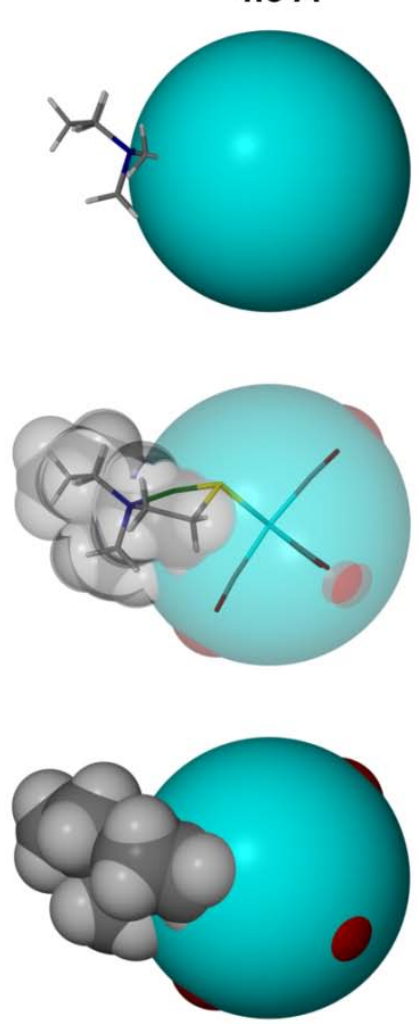

Figure 6. Renderings of 17, Ni(bme-dach)W(CO) $)_{4}$, showing percent volume buried based on the tungsten sitting at the center of a sphere with a radius of 3.5, 4.0, or $4.5 \AA$.

A)

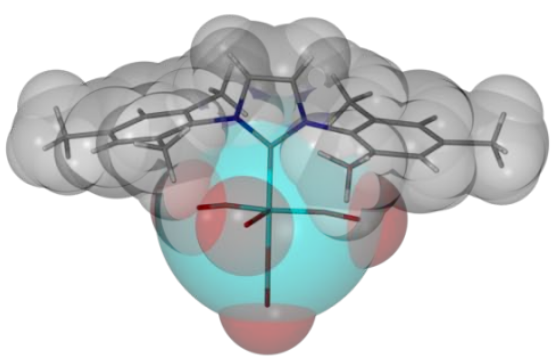

B)

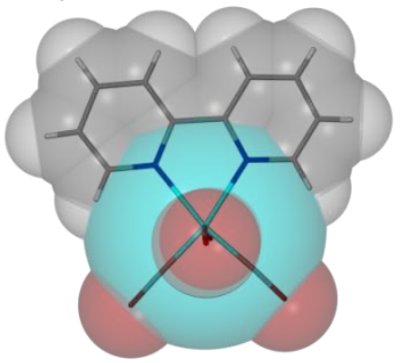

C)

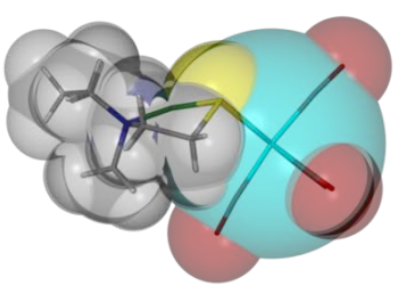

Figure 7. Percent buried volume (\% $\left.\mathrm{V}_{\mathrm{bur}}\right)$ using a sphere of $3.5 \AA$ radius for $\left.\mathrm{A}\right)(\mathrm{IMes}) \mathrm{Fe}(\mathrm{CO})_{4}$, 34.0\%; B) (bipy)W(CO) $)_{4}, 30.0 \%$; and, C) Ni(bme-dach)W(CO) 4 , 32.5\%. 
From the $\% \mathrm{~V}_{\text {bur }}$ values in Table 1 , we conclude that bipyridine, 13 , is the smallest ligand in its 3-dimensional spacial requirements; and dppm, 12, the largest. Intermediate between these two are eight $\mathrm{MN}_{2} \mathrm{~S}_{2}$ complexes which exhibit $\% \mathrm{~V}_{\text {bur }}$ values between 33 and $36 \%$. This narrow range is to be expected since these metalloligands are structurally very similar. The small differences between them are explained as follows: the $\mathrm{Ni}(\mathrm{ema})^{2-}, 22$, would be expected to be among the smaller complexes in this category and its $[\mathrm{V} \equiv \mathrm{O}]^{2+}$, analogue, 20 , would be larger due to the larger S to S distance and the concomitant expansion of the carbon alpha to sulfur and its hydrogens. The dependence of $\% \mathrm{~V}_{\text {bur }}$ on $\mathrm{S}$ to $\mathrm{S}$ distance is plotted in Figure $\mathrm{S} 4$ for various $\mathrm{MN}_{2} \mathrm{~S}_{2}$ metalloligands attached to the $\mathrm{W}(\mathrm{CO})_{4}$ unit. An obvious outlier in the data is complex 18, which is expected to have the greater steric bulk because of the gem-dimethyl groups on the alpha carbon.
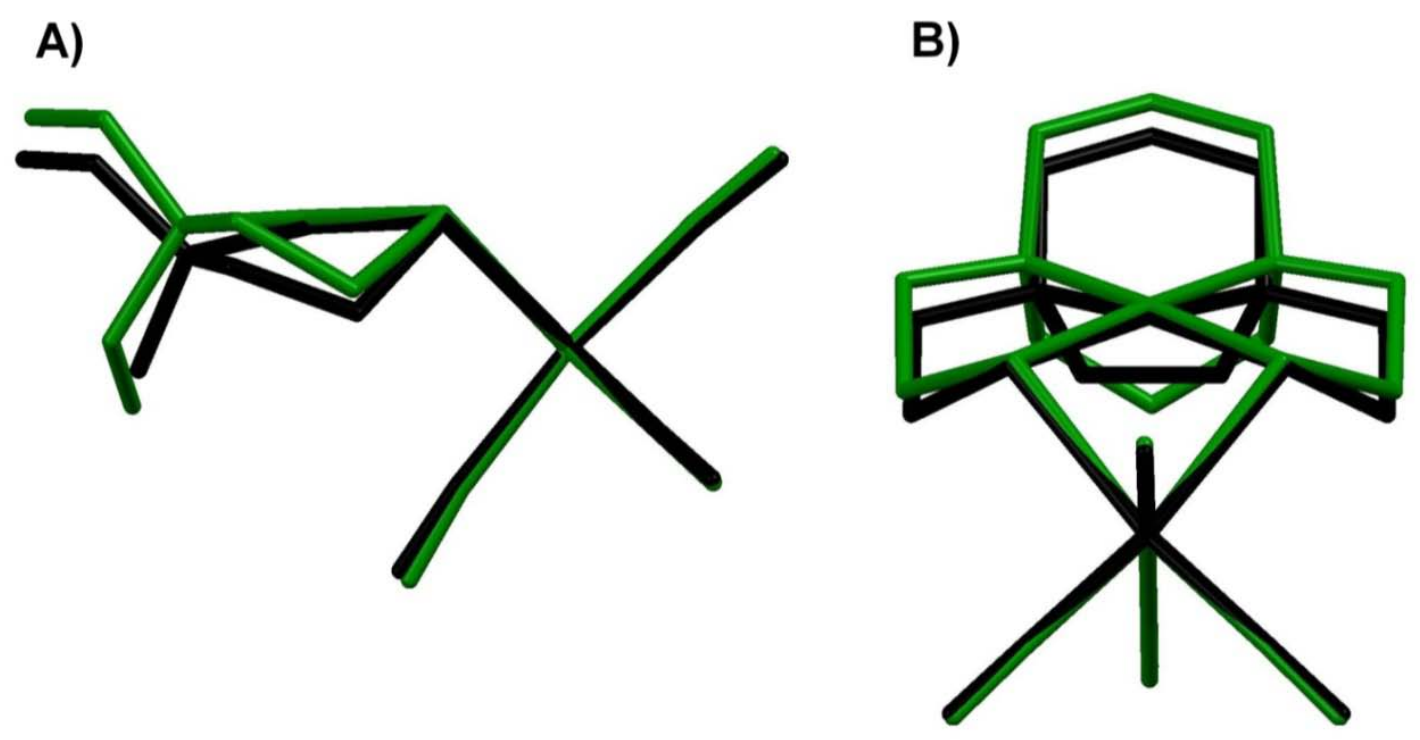

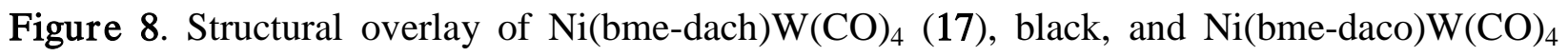
(19), green, shown from a A) side view and B) head-on view looking from the tungsten to the 
nickel. Note that the ethylene sulfide arms of $\mathbf{1 7}$ are closer to the tungsten center due to the torsion angles enforced by the more constricted diazacycle.

Of the three neutral $\mathrm{NiN}_{2} \mathrm{~S}_{2}$ complexes $17-19$, complex 18 with the gem-dimethyl groups is the largest. Despite the fewer atoms within complex 17, Ni(bme-dach), it occupies a larger percentage of space around the tungsten as compared to Ni(bme-daco), complex 19. The difference is ascribed to the greater $\mathrm{S}$ to $\mathrm{S}$ distance in the $\mathrm{Ni}$ (bme-dach) case. Secondly, as shown in Figure 8, the $\mathrm{N}_{2} \mathrm{~S}_{2}$ binding pocket of 17 is below the nickel and the ethylene $\mathrm{N}$ to $\mathrm{S}$ linkage sits further below the $\mathrm{N}_{2} \mathrm{~S}_{2}$ plane or closer to the tungsten than in the Ni(bme-daco) complex. This results in the carbon alpha to the sulfur occupying a larger space around the tungsten center. Both of these effects, the $S$ to $S$ distance and the displacement of the carbon alpha to sulfur, derives from the smaller, more constricted, diazacycloheptane mesocycle found in Ni(bmedach), Figure 8.

The last three complexes in this group, 15, 16, and 21, have 5-coordinate metal centers in the bme-dach framework. As well as the spacial requirement of the $5^{\text {th }}$ donor, the square pyramidality wherein the $\mathrm{N}_{2} \mathrm{~S}_{2}$ plane sits lower in comparison to their nickel analogues results in a greater displacement of the metal center from the best $\mathrm{N}_{2} \mathrm{~S}_{2}$ plane. Altogether these properties result in a greater spacial requirement of these metalloligands. The overlays of complexes $\mathbf{1 7}$ and 21, Figure S5A and 16 and 17, Figure S5B, illustrate the differences in steric requirements of penta-coordinate, square pyramidal vs. tetra-coordinate, square planar metalloligands. The $[\mathrm{Zn}(\mathrm{Cl})]^{+}$metalloligand in $\mathbf{2 1}$ can be considered the largest of these three due to the much greater S to S distance (3.412 $\AA$ ), Figure S5A. The $[\mathrm{Fe}(\mathrm{NO})]^{2+}$ metalloligand is slightly larger than its $[\mathrm{Co}(\mathrm{NO})]^{2+}$ analogue due to the lower positioning of the ethylene sulfide arms closer to the 
tungsten center in the $[\mathrm{Fe}(\mathrm{NO})]^{2+}$ complex; this can also be seen in the metal displacement from the $\mathrm{N}_{2} \mathrm{~S}_{2}$ plane 0.552 for $\mathrm{Fe}$ and $0.385 \AA$ for Co.

\section{Conclusion}

The steric and electronic properties of the $\mathrm{MN}_{2} \mathrm{~S}_{2}$ metalloligands may be tuned through modification of the metal center within the $\mathrm{N}_{2} \mathrm{~S}_{2}$ binding site, the organic linkers between $\mathrm{N}$ to $\mathrm{N}$ and $\mathrm{N}$ to $\mathrm{S}$ donor atoms, and the denticity of the $\mathrm{MN}_{2} \mathrm{~S}_{2}$ metalloligand towards the exogenous metal, M'. We have found it difficult to define the steric properties through approaches established for more common ligands. The examples described herein show that the steric pressure can come from the mercapto-arms as well as the $\mathrm{N}-$ to- $\mathrm{N}$ linker of the ligand. An additional steric feature noted in $\mathrm{MN}_{2} \mathrm{~S}_{2}$ metalloligands is the "nesting" effect shown toward the remaining ligand $\mathrm{L}$ in the $\mathrm{M}^{\prime} \mathrm{S}_{2} \mathrm{~L}$ facial arrangement. The organic linkers between donor atoms cradle this ligand which is situated under the $\mathrm{M}\left(\mathrm{N}_{2} \mathrm{~S}_{2}\right) \mathrm{M}^{\prime}$ tent or A-frame and provides steric shielding. We expect that such features can be tailored for specific additional ligands or substrates, and may be used to advantage in developing $\mathrm{MN}_{2} \mathrm{~S}_{2}$ metalloligands in bimetallic catalysis. 


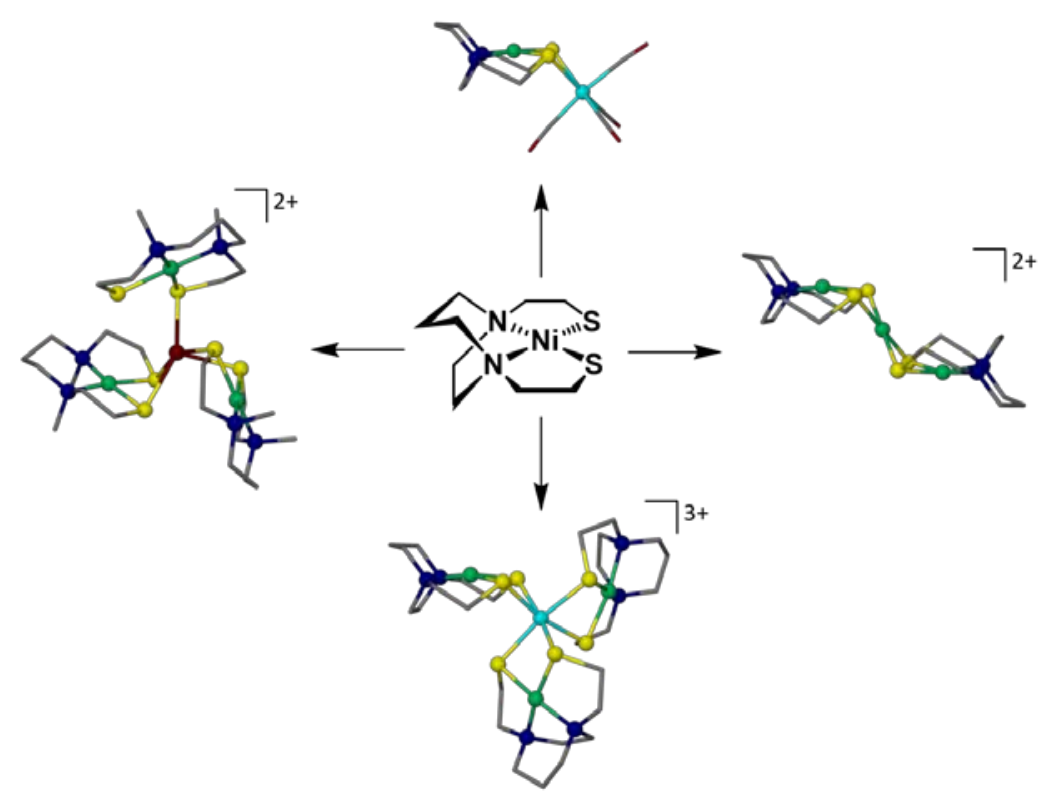

Figure 9. The highly versatile $\mathrm{NiN}_{2} \mathrm{~S}_{2}$ as a single bidentate ligand in $\mathrm{NiN}_{2} \mathrm{~S}_{2} \mathrm{~W}(\mathrm{CO})_{4}$, top; two metalloligands in $\left[\mathrm{NiN}_{2} \mathrm{~S}_{2}\right]_{2} \mathrm{Ni}^{2+}$, right; or three metalloligands in $\left[\mathrm{NiN}_{2} \mathrm{~S}_{2}\right]_{3} \mathrm{Rh}^{3+}$, bottom. Also illustrated by the $\left[\mathrm{NiN}_{2} \mathrm{~S}_{2}\right]_{3} \mathrm{Fe}^{2+}$ complex, left, is an example of hemi-lability and adaptability that serves to accommodate the binding preferences of the exogeneous metal, M'.

For application by the experimental/synthetic chemist, the number and type of ligands that may be accommodated by a metal ion in its optimal first-coordination sphere of donor atoms, is governed by the size of the donor atoms and their substituents as well as the possibility of fitting second coordination components into minimal space. None of the approaches that we described above directly apply to multiple $\mathrm{MN}_{2} \mathrm{~S}_{2}$ metalloligands on the same metal. Thus, Figure 9 provides examples of $\mathrm{MN}_{2} \mathrm{~S}_{2}$ metalloligands acting in complexes of the type $\left[\mathrm{NiN}_{2} \mathrm{~S}_{2}\right]_{\mathrm{x}} \mathrm{M}$ ' $(\mathrm{L})_{\mathrm{y}}$ where $\mathrm{x}=1$, 2, or 3 [1]. That is, with $\mathrm{Rh}^{3+}$, three $\mathrm{NiN}_{2} \mathrm{~S}_{2}$ ligands may complete the octahedral coordination preferred by $\mathrm{d}^{6}, \mathrm{Rh}^{3+}$; the $\mathrm{MN}_{2} \mathrm{~S}_{2}$ metalloligands fit themselves into a more or less pinwheel conformation [32]. The pentacoordinate $\left[\mathrm{NiN}_{2} \mathrm{~S}_{2}\right]_{3} \mathrm{Fe}^{2+}$ uses two $\mathrm{NiN}_{2} \mathrm{~S}_{2}$ in bidentate 
binding mode and one $\mathrm{NiN}_{2} \mathrm{~S}_{2}$ as a monodentate ligand to fulfill the electronic and geometrical preference of $\mathrm{Fe}^{2+}$ [33]. This example of hemi-lability highlights the versatility of the $\mathrm{MN}_{2} \mathrm{~S}_{2}$ metalloligands for creation of open sites. Remarkably these $\mathrm{MN}_{2} \mathrm{~S}_{2}$ metalloligands serve as bidentate bridging ligands to two metals in paddlewheel type complexes with $\mathrm{Zn}^{2+},\left[\mathrm{Rh}_{2}\right]^{2+}$, $\left[\mathrm{Mo}_{2}\right]^{2+}, \mathrm{Pd}^{2+}, \mathrm{Au}^{+}$, etc.; these were reviewed in a separate publication [1]. We posit that such, perhaps unmatched, adaptability of this class of $\mathrm{MN}_{2} \mathrm{~S}_{2}$ ligands awaits remarkable exploitations in coordination chemistry.

\section{Acknowledgements}

We wish to thank the National Science Foundation (CHE-1266097) and the R. A. Welch Foundation (A-0924) for funding. We appreciate the careful reading and comments of the editor and reviewers, that led us to a better conclusion.

\section{References}

[1] J.A. Denny, M.Y. Darensbourg, Chem. Rev., 115 (2015) 5248-5273.

[2] W.F. Liaw, C. Kim, M.Y. Darensbourg, A.L. Rheingold, J. Am. Chem. Soc., 111 (1989) 3591-3597.

[3] C.A. Tolman, Chem. Rev., 77 (1977) 313-348.

[4] M.V. Rampersad, S.P. Jeffery, M.L. Golden, J. Lee, J.H. Reibenspies, D.J. Darensbourg, M.Y. Darensbourg, J. Am. Chem. Soc., 127 (2005) 17323-17334.

[5] E. Almaraz, W.S. Foley, J.A. Denny, J.H. Reibenspies, M.L. Golden, M.Y. Darensbourg, Inorg. Chem., 48 (2009) 5288-5295.

[6] J.L. Hess, H.L. Conder, K.N. Green, M.Y. Darensbourg, Inorg. Chem., 47 (2008) 2056-2063. 
[7] T.A. Pinder, S.K. Montalvo, C.-H. Hsieh, A.M. Lunsford, R.D. Bethel, B.S. Pierce, M.Y. Darensbourg, Inorg. Chem., 53 (2014) 9095-9105.

[8] M.V. Rampersad, S.P. Jeffery, J.H. Reibenspies, C.G. Ortiz, D.J. Darensbourg, M.Y. Darensbourg, Angew. Chem. Int. Ed., 44 (2005) 1217-1220.

[9] A.L. Phelps, M.V. Rampersad, S.B. Fitch, M.Y. Darensbourg, D.J. Darensbourg, Inorg. Chem., 45 (2005) 119-126.

[10] C.-H. Lai, J.H. Reibenspies, M.Y. Darensbourg, Angew. Chem. Int. Ed., 35 (1996) 23902393.

[11] E. Bouwman, R.K. Henderson, A.L. Spek, J. Rë̈ł, Eur. J. Inorg. Chem., 1999 (1999) 217-219.

[12] A. Immirzi, A. Musco, Inorg. Chim. Acta, 25 (1977) L41-L42.

[13] H. Clavier, S.P. Nolan, Chem. Commun., 46 (2010) 841-861.

[14] R. Dorta, E.D. Stevens, N.M. Scott, C. Costabile, L. Cavallo, C.D. Hoff, S.P. Nolan, J. Am. Chem. Soc., 127 (2005) 2485-2495.

[15] F.A. Cotton, J.M. Troup, J. Am. Chem. Soc., 96 (1974) 3438-3443.

[16] R.L. Keiter, A.L. Rheingold, J.J. Hamerski, C.K. Castle, Organometallics, 2 (1983) 16351639.

[17] J. Pickardt, L. Rösch, H. Schumann, J. Organomet. Chem., 107 (1976) 241-248.

[18] P.E. Riley, R.E. Davis, Inorg. Chem., 19 (1980) 159-165.

[19] S. Warratz, L. Postigo, B. Royo, Organometallics, 32 (2013) 893-897.

[20] M.J. Aroney, I.E. Buys, M.S. Davies, T.W. Hambley, J. Chem. Soc., Dalton Trans., (1994) 2827-2834. 
[21] P. Braunstein, J.-p. Taquet, O. Siri, R. Welter, Angew. Chem. Int. Ed., 43 (2004) 59225925.

[22] G.W. Wong, J.L. Harkreader, C.A. Mebi, B.J. Frost, Inorg. Chem., 45 (2006) 6748-6755.

[23] Q. Ye, Q. Wu, H. Zhao, Y.-M. Song, X. Xue, R.-G. Xiong, S.-M. Pang, G.-H. Lee, J. Organomet. Chem., 690 (2005) 286-290.

[24] M.L.H. Green, J. Organomet. Chem., 500 (1995) 127-148.

[25] D.G. Gusev, Organometallics, 28 (2009) 6458-6461.

[26] J.M. Goldberg, G.W. Wong, K.E. Brastow, W. Kaminsky, K.I. Goldberg, D.M. Heinekey, Organometallics, 34 (2015) 753-762.

[27] T. Niksch, H. Görls, W. Weigand, Eur. J. Inorg. Chem., 2010 (2010) 95-105.

[28] A. Poater, B. Cosenza, A. Correa, S. Giudice, F. Ragone, V. Scarano, L. Cavallo, Eur. J. Inorg. Chem., 2009 (2009) 1759-1766.

[29] E. Alessio, M. Calligaris, M. Iwamoto, L.G. Marzilli, Inorg. Chem., 35 (1996) 2538-2545.

[30] A.R. Chianese, X. Li, M.C. Janzen, J.W. Faller, R.H. Crabtree, Organometallics, 22 (2003) 1663-1667.

[31] A.H. Velders, A.C.G. Hotze, G.A. van Albada, J.G. Haasnoot, J. Reedijk, Inorg. Chem., 39 (2000) 4073-4080.

[32] S.P. Jeffery, K.N. Green, M.V. Rampersad, J.H. Reibenspies, M.Y. Darensbourg, Dalton Trans., (2006) 4244-4252.

[33] G.J. Colpas, R.O. Day, M.J. Maroney, Inorg. Chem., 31 (1992) 5053-5055. 